\title{
Simultaneous CXCL12 and ESR1 CpG island hypermethylation correlates with poor prognosis in sporadic breast cancer
}

\author{
Edneia AS Ramos ${ }^{1}$, Anamaria A Camargo ${ }^{2}$, Karin Braun ${ }^{1}$, Renata Slowik', Iglenir J Cavalli ${ }^{3}$, Enilze MSF Ribeiro ${ }^{3}$, \\ Fábio de O Pedrosa ${ }^{4}$, Emanuel M de Souza ${ }^{4}$, Fabrício F Costa ${ }^{5}$, Giseli Klassen ${ }^{1 *}$
}

\begin{abstract}
Background: CXCL12 is a chemokine that is constitutively expressed in many organs and tissues. CXCL12 promoter hypermethylation has been detected in primary breast tumours and contributes to their metastatic potential. It has been shown that the oestrogen receptor $\alpha$ (ESR1) gene can also be silenced by DNA methylation. In this study, we used methylation-specific PCR (MSP) to analyse the methylation status in two regions of the CXCL12 promoter and ESR1 in tumour cell lines and in primary breast tumour samples, and correlated our results with clinicopathological data.

Methods: First, we analysed CXCL12 expression in breast tumour cell lines by RT-PCR. We also used 5-aza-2'deoxycytidine (5-aza-CdR) treatment and DNA bisulphite sequencing to study the promoter methylation for a specific region of CXCL12 in breast tumour cell lines. We evaluated CXCL12 and ESR1 methylation in primary tumour samples by methylation-specific PCR (MSP). Finally, promoter hypermethylation of these genes was analysed using Fisher's exact test and correlated with clinicopathological data using the Chi square test, KaplanMeier survival analysis and Cox regression analysis.

Results: CXCL12 promoter hypermethylation in the first region (island 2) and second region (island 4) was correlated with lack of expression of the gene in tumour cell lines. In the primary tumours, island 2 was hypermethylated in $14.5 \%$ of the samples and island 4 was hypermethylated in $54 \%$ of the samples. The ESR 1 promoter was hypermethylated in $41 \%$ of breast tumour samples. In addition, the levels of ER $\alpha$ protein expression diminished with increased frequency of ESR1 methylation $(p<0.0001)$. This study also demonstrated that CXCL12 island 4 and ESR1 methylation occur simultaneously at a high frequency $(p=0.0220)$.

Conclusions: This is the first study showing a simultaneous involvement of epigenetic regulation for both CXCL12 and ESR1 genes in Brazilian women. The methylation status of both genes was significantly correlated with histologically advanced disease, the presence of metastases and death. Therefore, the methylation pattern of these genes could be used as a molecular marker for the prediction of breast cancer outcome.
\end{abstract}

\section{Background}

Breast cancer development and progression is influenced by intrinsic properties of the tumour cells, as well as by macro-environmental factors. There is an extensive interplay between tumour cells and signalling molecules such as chemokines [1,2]. Chemokine receptors and growth factors have been extensively implicated in the metastatic process of breast cancer [3]. A chemokine-mediated

\footnotetext{
* Correspondence: giseli@ufpr.br

'Department of Basic Pathology, Federal University of Parana, Curitiba, Brazil
}

process of tumour cell homing to specific metastatic sites requires an enrichment in the site of metastasis formation for specific chemokines; these chemokines are then able to induce the migration of tumour cells that express the corresponding receptors [3]. CXCL12, formerly known as stromal cell-derived factor-1 (SDF-1 $\alpha$ ), is a CXC subfamily of chemokines that is expressed by stromal cells, including fibroblasts and endothelial cells. CXCL12 is also known to be present in the organs that are target for metastasis in breast cancer [1]. 
In cancer cells, gene expression is commonly altered due to a combination of genetic and epigenetic events. Aberrant gene silencing in mammalian cells is associated with promoter methylation, and it is known that many regions of the genome are methylated at one or more CpG sites [4,5]. Recent studies have also demonstrated that the CXCL12 gene modulates metastatic potential in breast and colon carcinomas, where it controls its own regulation in an autocrine loop. Epigenetic silencing causes the loss of autocrine expression and results in an imbalance in the expression levels of CXCL12 and its receptor, CXCR4 [6,7].

Sixty percent of primary breast tumours are ER $\alpha$-positive, and two-thirds of advanced breast tumours respond to therapy with anti-estrogens such as tamoxifen (Noval$\operatorname{dex}^{\oplus}$ ) [8]. However, a fraction of tumours that are ER $\alpha$ positive at diagnosis subsequently lose ER $\alpha$ expression during the progression of the disease [9]. Hypermethylation of the oestrogen receptor $\alpha$ gene (ESR1) is a common occurrence in several specific populations and for workers in a number of occupations; it seems to be a relevant factor for hormonal treatment $[10,11]$. In this study, we evaluated the methylation patterns of ESR1 and two CpG islands in the CXCL12 gene in breast tumour samples from Brazilian women. This is the first study to report an association between simultaneous DNA methylation of these two genes compared to other prognostic factors in breast cancer among Brazilian women.

\section{Methods}

\section{Cell Lines}

Breast tumour cell lines were all obtained from the Ludwig Institute for Cancer Research, (São Paulo, Brazil). The following cell lines were used: MDA-MB-436, MDA-MB-435, MDA-MB-231, MCF-7, PMC42, HB4a (control immortalized normal cells) [12] and HB4aC3.6 [13]. The cell lines were cultured in RPMI 1640 medium [14] containing $10 \%$ foetal bovine serum (supplemented with $0.2 \mathrm{mM}$ glutamine, and $40 \mu \mathrm{g} / \mathrm{mL}$ garamycin, 10 $\mu \mathrm{g} / \mathrm{mL}$ insulin, if necessary) at $37^{\circ} \mathrm{C}$ in a humidified incubator with $5 \% \mathrm{CO}_{2}$.

\section{Patient samples}

Frozen samples of breast tumours $(n=69)$ used for methylation analysis were obtained from patients treated by primary surgery for breast cancer at the Nossa Senhora das Graças Hospital, Curitiba, PR, Brazil with institutional approval (Process number 25000.007020/200393; CONEP register 7220 opinion number 251/2003). The study included only female patients with invasive breast tumours. All patients gave informed consent for the study to retain and analyse their tissue for research purposes. The ages of the patients ranged from 27 to 84 years (mean $57.8 \pm 14.7$ ). Histological types were either infiltrative ductal carcinoma (IDC) ( $\mathrm{n}=51,73.9 \%)$ or infiltrative lobular carcinoma (ILC) ( $\mathrm{n}=18,26.1 \%)$. The lymph node status of the patients was positive ( $\mathrm{n}=35$, $51.5 \%)$ or negative $(n=33,48.5 \%)$. Histologic grade was determined according to the modified Bloom-Richardson criteria. Of the patients, $27.6 \%$ were Grade I, $47.8 \%$ were Grade II and $24.6 \%$ were Grade III. TNM staging was done according to official classification methods [15]. Other clinicopathological data (tumour size, local recurrence, metastasis and death) are summarised in Table 1.

\section{Immunohistochemistry}

Standard immunohistochemical (IHC) detection was performed on sections from archival paraffin embedded breast tumour tissues. Protein expression in malignant breast tissues was detected with specific antibodies against estrogen receptor (ER) and progesterone receptor (PR); clones 1D5 and PgR 636 (DAKO), respectively. Monoclonal mouse anti-human antibodies were prediluted and incubated for $18 \mathrm{~h}$ at $4^{\circ} \mathrm{C}$ according to the manufacturer's instructions. The rabbit polyclonal antibody against HER2 detection was performed by the HercepTest $^{\mathrm{TM}}$ (DAKO CYTOMATION code K5204). In addition, positive and negative controls for each marker were routinely performed during experiments.

Sections were then processed using the EnVision ${ }^{\mathrm{Tm}}$ FLEX Target Retrieval Solution (DAKO) according to the manufacture's recommendations. Immunohistochemical staining of the samples was evaluated and scored by two pathologists who were responsible for clinicopathological data. The cutt-of value for ER and PR status values was $10 \%$ of cells. Fifty-seven ER $\alpha$-positive tumours were scored based on the number of positive cells present in IHC staining. The slides were scored following the criteria: $<10 \%$ tumour cells showing nuclear staining scored as $0,10-30 \%$ tumour cells showing nuclear staining scored as 1, 30-50\% tumour cells showing nuclear staining scored as $2,>50 \%$ tumour cells showing nuclear staining scored as 3 .

\section{RNA extraction and reverse transcription}

Total RNA was isolated using the TRIzol Reagent (Life Technologies, USA) according to the protocol supplied by the manufacturer. Reverse transcription reactions were performed using $500 \mathrm{ng}$ of DNA-free RNA, an oligo (dT) ${ }_{12-18}$ primer and Superscript II Reverse Transcriptase (Gibco, BRL). PCR was performed using CXCL12-specific primers, and GAPDH was used as a housekeeping control (Table 2). The PCR was performed in a volume of $20 \mu \mathrm{l}$ containing $1 \times$ PCR buffer (Invitrogen), $1.5 \mathrm{mM} \mathrm{MgCl}_{2}$ (Invitrogen), $200 \mu \mathrm{M}$ dNTPs, $0.3 \mu \mathrm{M}$ of each primer and $1 \mathrm{U}$ of Taq Platinum (Invitrogen). The PCR conditions were as follows: $95^{\circ}$ $\mathrm{C}$ for $10 \mathrm{~min}, 94^{\circ} \mathrm{C}$ for $45 \mathrm{~s}$, the appropriate annealing 
Table 1 Clinicopathological features of the 69 patients with primary breast carcinomas according to methylation status of CXCL12 and ESR1 genes

\begin{tabular}{|c|c|c|c|c|c|c|c|c|c|c|}
\hline \multirow[t]{2}{*}{ Variables } & \multirow[t]{2}{*}{ Samples (\%) } & \multicolumn{2}{|c|}{ CXCL12 methylation ${ }^{(a)}$} & \multirow[t]{2}{*}{$p^{a}$} & \multicolumn{2}{|c|}{ CXCL12 methylation ${ }^{(b)}$} & \multirow[t]{2}{*}{$p^{b}$} & \multicolumn{2}{|c|}{ ESR1 methylation ${ }^{(c)}$} & \multirow[t]{2}{*}{$p^{c}$} \\
\hline & & M (\%) & U (\%) & & M (\%) & U (\%) & & M (\%) & U (\%) & \\
\hline \multicolumn{11}{|l|}{ Age } \\
\hline$<45$ & $9(13)$ & 0 & $9(100)$ & 0.3378 & $3(33)$ & $6(67)$ & 0.2853 & $2(22)$ & $7(78)$ & 0.2937 \\
\hline$\geq 45$ & $60(87)$ & $10(17)$ & $50(83)$ & & $34(56.7)$ & $26(43.3)$ & & $26(43)$ & $34(57)$ & \\
\hline \multicolumn{11}{|l|}{ Stage } \\
\hline I & $13(19.7)$ & $2(15.4)$ & $11(84.6)$ & & $5(38.5)$ & $8(61.5)$ & & $1(7.7)$ & $12(92.3)$ & \\
\hline$\|$ & $31(47)$ & $5(16.1)$ & $26(83.9)$ & 0.9691 & $13(42)$ & $18(58)$ & 0.3696 & $10(32.3)$ & $21(67.7)$ & 0.0003 \\
\hline III/IV & $22(33.3)$ & $3(14)$ & $19(86)$ & & $13(59.1)$ & $9(40.9)$ & & $16(72.7)$ & $6(27.3)$ & \\
\hline \multicolumn{11}{|l|}{ Tumour size } \\
\hline pT1 & $19(27.6)$ & $4(21)$ & $15(79)$ & & $10(53)$ & $9(47)$ & & $4(21)$ & $15(79)$ & \\
\hline pT2 & $36(52.2)$ & $4(11.1)$ & $32(88.9)$ & 0.6088 & $17(47.2)$ & $19(52.8)$ & 0.3034 & $13(36.1)$ & $23(63.9)$ & 0.0029 \\
\hline pT3/pT4 & $14(20.2)$ & $2(14.3)$ & $12(85.7)$ & & $10(71.4)$ & $4(28.6)$ & & 11 (78.6) & $3(21.4)$ & \\
\hline \multicolumn{11}{|l|}{ SBR } \\
\hline I & $19(27.6)$ & $4(21.1)$ & $15(78.9)$ & & $7(36.8)$ & $12(63.2)$ & & $2(11)$ & $17(89)$ & \\
\hline$\|$ & 33 (47.8) & $4(12)$ & $29(88)$ & 0.4178 & 17 (39.4) & $16(60.6)$ & 0.0180 & $14(42.4)$ & 17 (57.6) & 0.0011 \\
\hline III & 17 (24.6) & $2(11.8)$ & 15 (88.2) & & $13(65)$ & $4(35)$ & & $12(71)$ & $5(29)$ & \\
\hline \multicolumn{11}{|c|}{ Lymph node status } \\
\hline Positive & $35(51.5)$ & 5 (14.3) & $30(85.7)$ & 1.0000 & $22(63)$ & $13(37)$ & 0.2231 & 19 (54.3) & $16(45.7)$ & 0.0288 \\
\hline Negative & $33(48.5)$ & $5(15.1)$ & $28(84.9)$ & & $15(45.4)$ & $18(54.6)$ & & $9(27.3)$ & $24(72.7)$ & \\
\hline \multicolumn{11}{|c|}{ Estrogen receptor } \\
\hline Positive & 57 (83.8) & 7 (12.2) & $50(87.8)$ & 0.6312 & $29(51)$ & $28(49)$ & 0.2084 & 19 (33) & $38(67)$ & 0.0054 \\
\hline Negative & $11(16.2)$ & $2(18.2)$ & 9 (81.8) & & $8(73)$ & $3(27)$ & & $9(81.8)$ & $2(18.2)$ & \\
\hline \multicolumn{11}{|l|}{ HER2 } \\
\hline Positive & $20(31.3)$ & $5(25)$ & $15(75)$ & 0.0955 & $12(60)$ & $8(40)$ & 0.5996 & $10(50)$ & $10(50)$ & 0.4249 \\
\hline Negative & $44(68.7)$ & $3(6.9)$ & 41 (93.1) & & $23(52.3)$ & $21(47.7)$ & & 17 (38.6) & $27(61.4)$ & \\
\hline \multicolumn{11}{|c|}{ Progesterone receptor } \\
\hline Positive & $45(65)$ & $7(17)$ & $38(83)$ & 1.0000 & $25(56)$ & $20(44)$ & 1.0000 & $16(36)$ & $29(64)$ & 0.0808 \\
\hline Negative & $16(35)$ & $2(12.5)$ & $14(87.5)$ & & $9(56.3)$ & $7(43.7)$ & & $10(62.5)$ & $6(37.5)$ & \\
\hline \multicolumn{11}{|l|}{ Metastasis } \\
\hline Positive & $15(22.4)$ & $3(20)$ & $12(80)$ & 0.4075 & $14(93)$ & $1(7)$ & 0.0008 & $13(86.7)$ & $2(13.3)$ & $<0.0001$ \\
\hline Negative & $52(77.6)$ & $6(11.5)$ & $46(88.5)$ & & $23(44)$ & $29(56)$ & & $14(26.9)$ & $38(73.1)$ & \\
\hline \multicolumn{11}{|l|}{ Recurrence } \\
\hline Positive & $8(12)$ & $2(25)$ & $6(75)$ & 0.3413 & $6(75)$ & $2(25)$ & 0.2700 & $4(50)$ & $4(50)$ & 0.7049 \\
\hline Negative & $59(88)$ & $8(13.5)$ & $51(86.5)$ & & $30(51)$ & 29 (49) & & 23 (39) & $36(61)$ & \\
\hline \multicolumn{11}{|l|}{ Death } \\
\hline Positive & $17(26)$ & $4(23.5)$ & $13(76.5)$ & 0.2250 & $15(88)$ & $2(12)$ & 0.0019 & $13(76.5)$ & $4(23.5)$ & 0.0013 \\
\hline Negative & $48(74)$ & $5(10.4)$ & 43 (89.6) & & $21(43.7)$ & $27(56.3)$ & & 14 (37.8) & $33(62.2)$ & \\
\hline \multicolumn{11}{|c|}{ Histological type } \\
\hline IDC & $51(73.9)$ & $8(15.7)$ & $43(84.3)$ & 1.0000 & $30(58.8)$ & $21(41.2)$ & 0.1759 & $20(39.2)$ & $31(60.8)$ & 0.7829 \\
\hline ILC & $18(26.1)$ & $2(11.1)$ & $16(88.9)$ & & 7 (39) & $11(61)$ & & $8(44.4)$ & $10(55.6)$ & \\
\hline
\end{tabular}

Abbreviations: a, data of CXCL12 CpG island-2; b, data of CXCL12 CpG island-4; $c$, data of ESR1 gene; $p$, value from statistical analysis $\chi^{2}$ test and Fisher's exact test; $M$, methylation results; $U$, unmethylation results; significant data are in bold.

temperature for $45 \mathrm{~s}, 72^{\circ} \mathrm{C}$ for $1 \mathrm{~min}$ and a final extension of $72^{\circ} \mathrm{C}$ for $5 \mathrm{~min}$. PCR products were resolved on $1 \%$ agarose gels and visualised by ethidium bromide staining.

\section{5-aza-2'-deoxycytidine (5-aza-CdR) treatment}

The cell lines MDA-MB-231, MDA-MB-435 and MDAMB-436 were analysed using this technique. Cells were plated $\left(10^{6} \mathrm{cells} / \mathrm{ml}\right)$ and treated for 7 days with $1 \mu \mathrm{M}$
5-aza-CdR (Sigma Aldrich, Deisenhein, Germany) or left untreated. The medium was changed every day, and no significant cell death was observed. After 7 days of treatment, total RNA was isolated. The expression of CXCL12 in breast tumour cells was analysed by RTPCR using the housekeeping gene GAPDH as an internal control. PCR products were resolved on $1 \%$ agarose gels and visualised by ethidium bromide staining. 
Table 2 Summary of primer sequences, used for RT-PCR, nested-PCR and MSP

\begin{tabular}{|c|c|c|c|c|c|c|}
\hline Application and specificity & CpG status & Forward primer $\left(5^{\prime}-3^{\prime}\right)$ & Reverse primer $\left(5^{\prime}-3^{\prime}\right)$ & $\begin{array}{l}\text { Product } \\
\text { size (bp) }\end{array}$ & $\begin{array}{c}\text { Annealing } \\
\mathrm{T}\left({ }^{\circ} \mathrm{C}\right)\end{array}$ & Ref. \\
\hline \multicolumn{7}{|l|}{ RT-PCR } \\
\hline CXCL12 & - & CAACGTCAAGCATCTCAA & AGCTGCAATATCATACCGTA & 383 & 58 & This work \\
\hline GAPDH & - & CTGCACCACCAACTGCTT A & CATGACGGCAGGTCAGGTC & 296 & 63 & \\
\hline \multicolumn{7}{|l|}{ nested-PCR } \\
\hline CXCL12 & - & GTAGTGAGGTTTAGTGAAG & CCATAAATACCACAATAACTTC & 479 & $51,53,55$ & This work \\
\hline CXCL12-nested & - & AGGTTITGTTGGGTTGG & CAAATCCTAAATCCAACTAC & 338 & $53,55,57$ & \\
\hline SATR-1 & - & GTTATATTATITITGTIIIITG & ACATTTCCTTATAATATTATTCC & - & $48,50,52$ & [21] \\
\hline SATR-1 nested & - & TATAGTGGTGGTGTATATTTG & СACCTAACCTATAATATTTCTTC & 690 & $52,54,56$ & \\
\hline \multicolumn{7}{|l|}{ MSP } \\
\hline CXCL12- (2) & U & GAGTTTGAGAAGGTTAAAGGTTGG & CAAAAAATAAAAATACAACA & 249 & 50 & {$[7]$} \\
\hline CXCL12- (2) & M & GTTAAAGGTCGGAGCGTATTG & ACGAAAAATAAAAATACGACGAT & 237 & 59.5 & \\
\hline CXCL12- (4) & U & GTCGTAGCGTTGGGGTT & AACGAAACTACGCGCGACT & 200 & 57.8 & This work \\
\hline CXCL12- (4) & M & GTTGTAGTGTTGGGGTTI & AAACAAACAAAACTACA & 189 & 64 & \\
\hline ESR1 & M & ACGAGTTTAACGTCGCGGTC & ACCCCCCAAACCGTTAAAAC & 140 & 57.6 & {$[20]$} \\
\hline
\end{tabular}

Abbreviations: $\mathrm{M}$, specific for methylated condition; $\mathrm{U}$, specific for unmethylated condition; (2), primers designed for CpG island 2; (4), primers designed for CpG island 4; ESR1, estrogen receptor gene.

\section{DNA isolation and sodium bisulphite treatment}

Genomic DNA was prepared from breast cancer cell lines or frozen tumour samples by the phenol/chloroform protocol [16]. They were then subjected to sodium bisulphite treatment using the EpiTect ${ }^{\bullet}$ Bisulphite Kit (Qiagen) according to the manufacturer's instructions.

\section{CXCL12 CpG island methylation analysis}

Previous studies used the MSP technique to evaluate the regulation of CXCL12 expression by DNA methylation and in this study we have utilized the designed primers for this region (island 2), as described [7].

In an attempt to determine all $\mathrm{CpG}$ islands and all potential transcription start sites (TSS) for CXCL12, we first proceeded with the identification of the promoter sequence [17]. The analyses were initiated using an identified RefSeq by GenBank accession number, after which we submitted the gene sequence to a Genome BLAT Search through the UCSC Genome bioinformatics website http://genome.ucsc.edu. We selected 2000 bps of sequence extending from the 5' upstream region to $1000 \mathrm{bps}$ downstream of the region of the TSS. The BLAT program returned a sequence of 5677 bps that was first submitted to the CpGPLOT program from the European Bioinformatics Institute website http://www.ebi.ac.uk/emboss/cpgplot. This program defines a CpG island as $\geq 200$ bps of sequence with $\geq$ $50 \% \mathrm{C}+\mathrm{G}$ content and $\geq 0.6 \mathrm{CpG}$ observed/CpG expected. The 5677 bps from CXCL12 that we have analysed contained five CpG islands in a region of 3447 bps (Figure 1A). The 5677 bps sequence was also submitted to computational analysis to predict transcription factor binding sites using TESS http://www.cbil.upenn.edu/cgibin/tess/tess and MatInspector http://www.genomatix. de/[18]. The DNA region we refer to as island 4 (Figure $1 \mathrm{~A}$ ) is positioned next to an estrogen responsive element (ERE) binding site that could be involved in breast cancer. This CpG island was also selected for methylation status analyses in this study.

Island 4 was amplified from bisulphite-treated DNA samples using a nested-PCR amplification protocol. The two sets of primers were used for the nested reactions at their appropriate annealing temperatures, and are shown in Table 2 . The first PCR reactions were performed as described below: 1 cycle of $95^{\circ} \mathrm{C}$ for $10 \mathrm{~min}$, $94^{\circ} \mathrm{C}$ for $3 \mathrm{~min}$, the appropriate annealing temperature for $3 \mathrm{~min}, 72^{\circ} \mathrm{C}$ for $2 \mathrm{~min} ; 5$ cycles of $94^{\circ} \mathrm{C}$ for $3 \mathrm{~min}$, annealing temperature for $3 \mathrm{~min}, 72^{\circ} \mathrm{C}$ for $2 \mathrm{~min} ; 35$ cycles of $94^{\circ} \mathrm{C}$ for $1 \mathrm{~min}$, annealing temperature for 1 min, and $72^{\circ} \mathrm{C}$ for $5 \mathrm{~min}$. Amplified products were purified using the Qiaquick Gel Extraction Kit (Qiagen) and cloned into a pCR2.1 cloning vector (Invitrogen). Eight clones were sequenced for each cell line using the universal or reverse primers. DNA sequencing reactions were performed using Big Dye Terminator technology (Applied Biosystems) on an ABI 377 sequencer (Applied Biosystems) according to the manufacturer's instructions. One hundred percent methylation was obtained if a methylated cytosine in the CpG dinucleotides was present in eight sequenced clones. The methylation percentage for each tumour cell line (global methylation pattern) was calculated by dividing the number of methylated CpG dinucleotides by the total number of CpGs analysed.

\section{Methylation-specific PCR (MSP)}

Methylation-specific PCR was performed as previously described [19] and the CXCL12 primer sequences for 


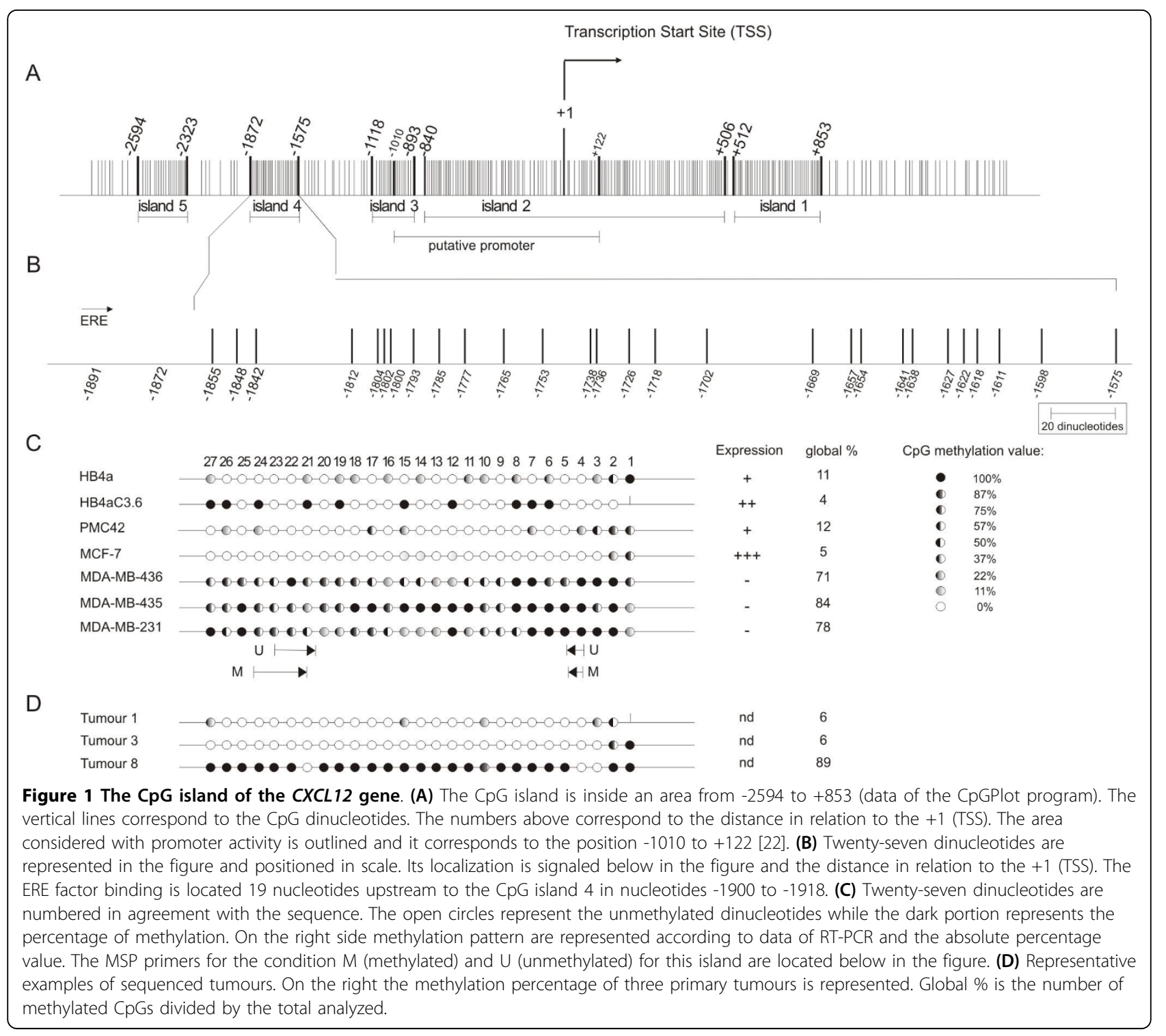

island 2 [7] can be visualized in the Table 2. gDNA from the primary breast tumours was bisulphite-modified and amplified with CXCL12 primers specific for methylated (M) and unmethylated (U) DNA. Analysis of methylation of the ESR1 promoter was performed using the set of primers described by Li et al. [20]. PCR reactions were performed with $1 \mu \mathrm{L}$ of modified DNA, $1 \times$ PCR Buffer (Invitrogen), $1.5 \mathrm{mM}$ (for CXCL12) or 2.5 $\mathrm{mM}$ (for ESR1) of $\mathrm{MgCl}_{2}$ (Invitrogen), $200 \mu \mathrm{M}$ dNTPs, $0.3 \mu \mathrm{M}$ of each primer and $1 \mathrm{U}$ of Taq Platinum (Invitrogen). The PCR protocol was $95^{\circ} \mathrm{C}$ for $10 \mathrm{~min} ; 38$ cycles of $94^{\circ} \mathrm{C}$ for $45 \mathrm{~s}$, the appropriate annealing temperature for $30 \mathrm{~s}$ and $72^{\circ} \mathrm{C}$ for $45 \mathrm{~s}$, followed by a final extension of $72^{\circ} \mathrm{C}$ for $5 \mathrm{~min}$. DNA modification was confirmed by a nested-PCR reaction with a set of primers for a previously described satellite region
(Table 2). This reaction was used as a control for bisulphite modification quality [21]. This PCR reaction, the nested-PCR and temperature conditions are described in Table 2. The amplification products were separated on $2 \%$ agarose gels and stained with ethidium bromide.

\section{Statistical analysis}

The statistical analysis was carried out using SPSS program (version 16.0, SPSS Inc., Chicago, Illinois, USA). Associations between specific clinicopathological parameters were analyzed using Chi square test and Fisher's exact test. Statistical significance was assumed for $p<$ 0.05. The overall survival was calculated from the time of diagnoses of disease to the occurrence of death. Survival data were censored on $30^{\text {th }}$ June, 2009, which was the date in which the survival data were correlated with 
the death registry for the last time of a means of 91 months after onset of the disease. Kaplan-Meier estimates are presented for the survival functions, and differences in survival were analyzed using the log rank test. Multivariate analysis was conducted with a backward application of Cox proportional hazards regression analysis was used to estimate hazards ratio (HR) and 95\% confidence intervals (95\% CI) for overall survival and metastasis-free survival. All covariates with $\mathrm{p}<0.25$ were retained in the final model.

\section{Results}

\section{CXCL12 expression in breast tumour cell lines}

We first analysed the CXCL12 expression pattern in seven breast tumour cell lines using RT-PCR. A transcript of 383 bps corresponding to the CXCL12 gene was detected in the less aggressive carcinoma cell lines MCF7 and PMC42, in the normal cell line HB4a and in the modified normal cell line HB4aC3.6 with ERBB2 overexpression (Figure 2A). In contrast, no detectable levels of CXCL12 expression were observed in the highly aggressive tumour cell lines MDA-MB-435, MDA-MB-436 or MDA-MB-231. To definitively determine if CXCL12 expression was, in fact, lost, all analyses were repeated at least twice. GAPDH expression was detected in all samples (Figure 2A). These data are in agreement with the literature [6], except in the case of the normal cell lines and the tumour cell lines MDA-MB-436 and PMC42, where such data have not been previously described.

\section{CXCL12 silencing by DNA methylation}

To confirm the epigenetic transcriptional silencing of CXCL12, we treated the MDA-MB-435, MDA-MB-436 and MDA-MB-231 breast tumour cell lines with the demethylating agent 5-aza-2'-deoxycytidine (5-aza-CdR). The expression of CXCL12 was restored in MDA-MB435 cells upon treatment as previously observed [6]. Expression of CXCL12 was also restored in MDA-MB231 cells, but not in MDA-MB-436 cells (Figure 2B).

The CpGPlot program analysis of 5677 bps of the $5^{\prime}$ region of the CXCL12 gene identified five putative islands in the CXCL12 promoter region. The CpG island is positioned in an area extending from -2594 to +853 (Figure $1 \mathrm{~A})$. In this region, five distinct $\mathrm{CpG}$-rich regions were identified in the positions +512 to +853 (island 1), -840 to +506 (island 2 ), -1118 to -893 (island 3 ), -1872 to -1575 (island 4) and -2594 to -2323 (island 5). The region comprised of island 2 studied in the breast and colon carcinomas $[6,7]$ was -493 to +168 relative to the TSS and
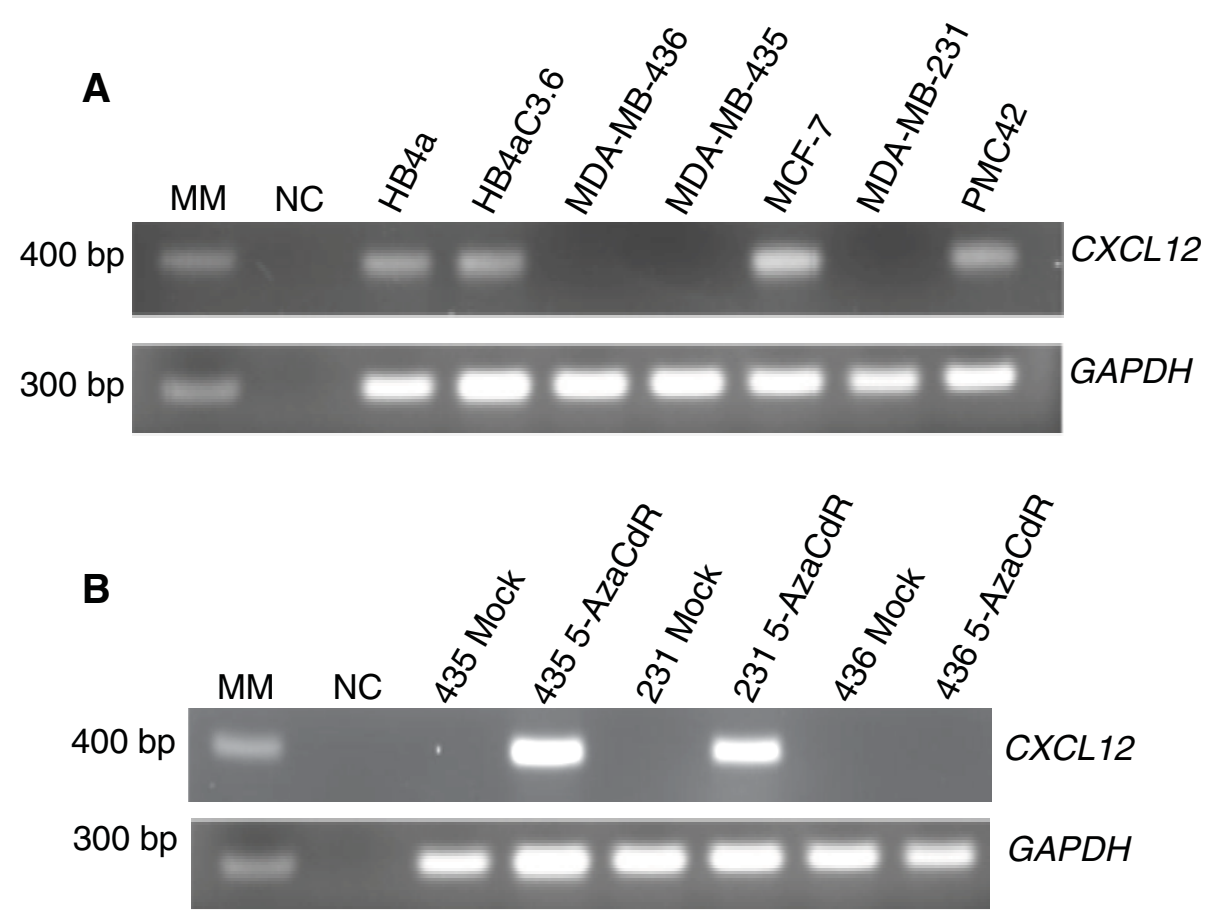

Figure 2 CXCL12 expression in breast normal and tumour cell lines and expression after 5-aza-2'-deoxycytidine (5-aza-CdR) treatment (A) The bands represent positive results for CXCL12 expression (383 bps) and GAPDH gene was used as housekeeping control (296 bps). (B) CXCL12 expression evaluation after 5-aza-CdR treatment in MDA-MB-435, MDA-MB-436 and MDA-MB-231 cell lines. The cell lines named Mock were not treated, and those named 5-aza-CdR were treated showing the re-expression of CXCL12 on these cell lines. $\mathrm{H}_{2} \mathrm{O}$ was used as negative control and MM 100 bp was used as a molecular weight marker. 
promoter activity was found in the region from -1010 to +122 [22]. The search for transcription factor binding sites by computational analysis revealed eight oestrogen responsive element (ERE) consensus sites, which are defined as 13 bps perfect palindromic inverted repeats with a 3 bps spacing of variable bases (n) 5'GGTCAnnnTGACC 3' [23]. Five of these sites are very distant from the TSS, two are inside island 2 and the essential GACC sequence is absent. Only one site with the sequence aGctgctggGACC (capital letters for those that match with the consensus), which lies 19 bps away from island 4, might be an oestrogen-binding site (Figure 1B). Therefore, we complemented our tumour sample analysis with MSP for CXCL12 CpG island 4.

Sodium bisulphite sequencing was carried out on a 297 bps DNA fragment containing 27 CpG dinucleotides (-1872 to -1575$)$ (Figure 1B). We analysed the methylation pattern of eight independent alleles (eight clones) from HB4a and $\mathrm{HB} 4 \mathrm{aC} 3.6$ normal cell lines, as well as the PMC42, MCF-7, MDA-MB-436, MDA-MB435, MDA-MB-231 breast tumour cell lines. The methylation pattern varied among the different cell lines as shown in Figure $1 C$. The $C X C L 12$-negative cell lines, MDA-MB-436 (71\%) MDA-MB435 (84\%) and MDAMB-231 (78\%) showed CpG dinucleotide hypermethylation. In contrast, the CXCL12-positive cell lines, HB4a (11\%), HB4aC3.6 (4\%), PMC42 (12\%) and MCF-7 (5\%), had lower levels of $\mathrm{CpG}$ dinucleotide methylation (Figure $1 \mathrm{C}$ ). These results were in agreement with our expression analysis (Figure 2A). On the other hand, the breast tumour cell line MDA-MB-436 had a dense area of methylated DNA and did not regain expression of the CXCL12 gene when cultured with the demethylating agent 5-aza-CdR (Figure 2B). The importance of DNA methylation in cancer has been well established [24], and the focus in the field is now changing to include the mechanisms by which other chromatin modifications play a role in cancer development. Among these changes are the covalent modifications of histones that can control gene activity. Histone acetylation and methylation of specific lysine residues, such as lysine 9 in histone $\mathrm{H} 3$ or lysine 27 in histone H3, clearly participate in the silencing of genes [25].

We also evaluated the CpG dinucleotide sequence for island 4 in the primary breast tumour samples 1,3 and 8 (Figure 1D). These samples were chosen from the MSP data analysis, and we have confirmed the pattern that was described.

\section{MSP analysis in breast tumour cell lines}

Dinucleotides 4 and 5, and 21-24, which were chosen for the design of methylation-specific PCR (MSP) primers, lie within a region that is differentially methylated (Figure 1C). The MSP technique was tested with
CXCL12 (island 2 and island 4) and ESR1 genes in DNA from the tumour cell lines in order to confirm the results from RT-PCR and data from the literature (ESR1). The CXCL12 MSP results from breast tumour cell lines were identical for the two islands (Figure 3A). The MDA-MB-436, MDA-MB-435 and MDA-MB-231 breast tumour cell lines showed methylation of the two islands, which is in agreement with the observed lack of CXCL12 expression. In contrast, the HB4a, HB4aC3.6, MCF-7 and PMC42 cell lines expressing CXCL12 showed no methylated bands (Figure 3A).

The ESR1 MSP results showed hypermethylation in the MDA-MB-436, MDA-MB-435 and MDA-MB-231 breast tumour cell lines as well as in the HB4aC3.6 normal cell line. The HB4a normal cell line and the MCF-7 and PMC42 breast tumour cell lines did not show any methylated bands (Figure 3A). These data corroborate the literature $[10,26]$ except in the case of cell lines MDA-MB-436, PMC42 and HB4aC3.6, which have not been previously described.

In this work, we did not evaluate normal breast tissue, but Zhou et al. [27] used twenty normal samples and all of them showed CXCL12 expression without methylation, which is in agreement with a possible tumoral methylation specificity observed in our results.

\section{MSP analysis in primary breast tumours}

The MSP assay was subsequently used to analyse primary breast tumour samples. All samples showed the band corresponding to the unmethylated state for islands 2 and 4 (data not shown). Based on these results, we can conclude that the samples have cellular heterogeneity due to the presence of normal tissue or infiltrating lymphocytes.

For the methylated condition, nine representative tumour samples are shown (Figure 3B). Of all the samples tested (69), only four were methylated at both islands, and three of these samples methylated at both genes (Figure 3B). Moreover eighteen samples were methylated in both, CXCL12 island 4 and ESR1 genes $(p=0.0220)$. This finding indicates a strong correlation between the promoter methylation of ESR 1 and CXCL12 island 4. In other words, methylation of the ESR1 promoter could be involved in directing the methylation of island 4 (see more details in discussion).

We also wanted to confirm that the presence or absence of island 2 or island 4 methylation observed in MSP (Figure 3B) was not just a PCR artefact. Therefore, we sequenced island 4 isolated from tumour samples 1 , 3 and 8 (representative for banding pattern). Island 4 displayed $6 \%$ methylation in samples 1 and 3, and $89 \%$ methylation in sample 8 (Figure 1D). These results are in agreement with the PCR bands observed in the MSP. 


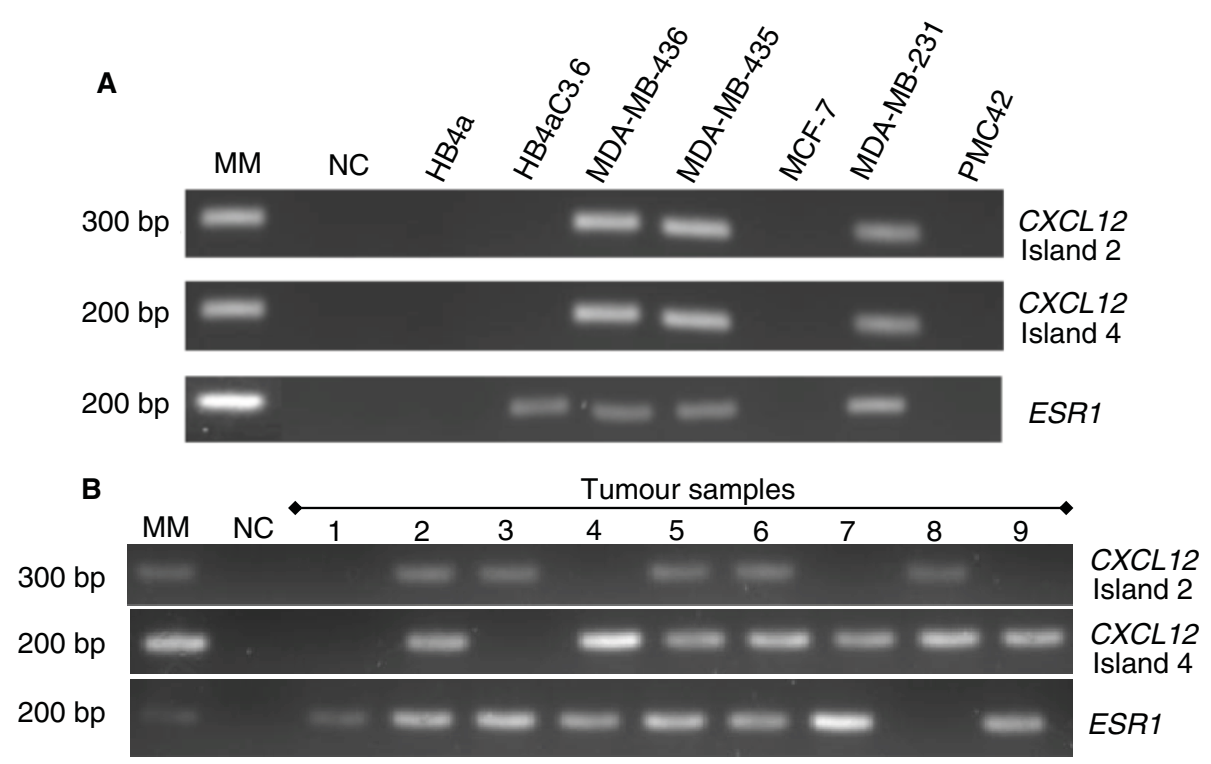

Figure 3 CXCL12 and ESR1 methylation analyses of breast normal and tumour cell lines and MSP in primary breast tumours. (A) MSP was performed using bisulphite treated DNA with primers that recognize methylated promoter only. The bands represent positive results for the methylation in the islands 2 and 4 for $C X C L 12$ and ESR1 genes. $\mathrm{H}_{2} \mathrm{O}$ was used as template in the negative control (NC). (B) Nine of sixty-nine representative samples are included in the figure. Tumour samples were subjected to the MSP reaction, confirming the standardization done with the cell lines for the methylated condition. The results for ESR1 showed promoter methylation in the samples 1 to 7 and 9 . The tumour 1 presented both islands negative for methylation of CXCL12 gene; however ESR1 methylation was present even thought this sample is ER $\alpha$ positive. The tumour 8 represented a sample with unmethylated ESR1. The lanes 1, 3 and 8 were representative sequenced samples after bisulphite treatment (see Figure 1D).

The correlation between CXCL12 and ESR1 promoter methylation status with patient clinicopathological data The correlation between the CpG islands of CXCL12 and ESR1 methylation and the clinicopathological parameters of our samples are shown in Table 1. For island 2, CXCL12 methylation was observed in ten of 69 (14.5\%) samples and was not significantly associated with any clinicopathological data (Table 1a). For island 4, CXCL12 methylation was observed in 37 of 69 (54\%) samples. The clinicopathological parameters are shown in Table $1 \mathrm{~b}$ and hypermethylation in this region was significantly associated with histological grade $\operatorname{SBR}(p=0.0180)$, metastasis $(p=0.0008)$ and death $(p=0.0019)$. These results suggested that $\mathrm{CpG}$ island 4 might be important as a factor for poor prognosis of disease. In order to test this hypothesis we evaluated all of the clinicopathological data for their prognostic value in a univariate analysis for overall survival (OS) and metastasis-free survival (MFS) using Kaplan-Meier analysis ( $p$ value for log rank test). The overall survival (OS) was significantly worse for many clinicopathological parameters, which are shown in additional file 1 . The graphical results for OS and MFS are shown in Figure 4 for ESR 1 and CXCL12. The OS correlated with ESR1 $(p=0.0009)$ and CXCL12 island 4 $(p=0.0071)$ methylation (Figure $4 \mathrm{~A}$ and $4 \mathrm{~B}$ respectively). The metastasis-free survival correlated with ESR1 and
CXCL12 island 4 (for both, $p<0.0001$ ) (Figure 4C and $4 \mathrm{D}$, respectively). The Kaplan-Meier analysis showed that the overall survival and metastasis-free survival were significantly shorter when silencing of CXCL12 island 4 and ESR1 occurred by gene hypermethylation. The effects of the covariables on OS and MFS were examined in the Cox proportional hazard regression model. The results for the univariate analysis are shown in Table 3 . In the multivariate analysis, all variables presenting $p<0.2$ from the univariate analysis were selected to build the multiple model (Table 3). For overall survival, the presence of metastasis $(p=0.0022)$ was considered a prognostic factor and ESR1 hypermethylation showed a statistical trend $(p=0.0555)$. Besides ER $\alpha$, the hypermethylation of CXCL12 island 4 and ESR1 genes $(p=0.0302, p=0.0089$ and $p=0.0046$, respectively) was considered an independent prognostic factor for metastasis-free survival. Patients with ER $\alpha$ protein present had the lowest risk of metastasis development (HR 0.3343; 95\% CI 0.1247$0.8963)$. Otherwise, patients with methylation at both CXCL12 island 4 and ESR1 genes had a risk of developing metastasis, with CXCL12 island 4 having the highest risk (HR 7.1355; 95\% CI 1.6480-30.8958).

ESR 1methylation was observed in 28 of 69 (41\%) tumour samples (Table 1c) and was not significantly associated with age, HER2 or progesterone receptor 
Table 3 Time to breast cancer progression in relation to clinicopathological characteristics: Cox proportional hazards model

\begin{tabular}{|c|c|c|c|c|c|c|}
\hline \multirow[t]{2}{*}{ Analysis } & \multicolumn{3}{|c|}{ Overall survival } & \multicolumn{3}{|c|}{ Metastasis-free survival } \\
\hline & $\mathrm{HR}$ & $95 \% \mathrm{Cl}$ & $p$ value & HR & $95 \% \mathrm{Cl}$ & $p$ value \\
\hline \multicolumn{7}{|l|}{ Univariate } \\
\hline Age & 1.0074 & 0.9717 to 1.0444 & 0.6901 & 1.0134 & 0.9791 to 1.0490 & 0.4507 \\
\hline Stage & 2.8065 & 1.1063 to 7.1200 & 0.0306 & 3.3893 & 1.4386 to 7.9850 & 0.0054 \\
\hline Grade & 8.3473 & 1.1141 to 62.5437 & 0.0399 & 10.0599 & 1.3565 to 74.6075 & 0.0246 \\
\hline Tumour size & 2.8301 & 1.0906 to 7.3445 & 0.0333 & 2.8825 & 1.1909 to 6.9770 & 0.0195 \\
\hline Lymph node & 2.1072 & 0.9382 to 4.7326 & 0.0724 & 1.8045 & 0.8696 to 3.7445 & 0.1148 \\
\hline ER $\alpha$ & 0.3322 & 0.1191 to 0.9265 & 0.0361 & 0.2413 & 0.0971 to 0.5992 & 0.0023 \\
\hline HER2 & 0.6813 & 0.3044 to 1.5247 & 0.3529 & 0.8075 & 0.4005 to 1.6280 & 0.5521 \\
\hline PR & 0.727 & 0.3487 to 1.5159 & 0.3976 & 0.527 & 0.2614 to 1.0627 & 0.0749 \\
\hline Recurrence & 2.0282 & 0.7885 to 5.2175 & 0.1444 & 1.7645 & 0.9107 to 3.4189 & 0.0940 \\
\hline Metastasis & 7.824 & 2.7957 to 21.8962 & $<0.0001$ & & & \\
\hline Death & & & & 2.4134 & 1.3737 to 4.2402 & 0.0022 \\
\hline Histological type & 0.9002 & 0.2937 to 2.7597 & 0.8549 & 0.6848 & 0.2292 to 2.0455 & 0.4998 \\
\hline CXCL12 Island 4 & 4.1124 & 1.3539 to 12.4913 & 0.0130 & 11.5151 & 2.6886 to 49.3180 & 0.0010 \\
\hline CXCL12 Island 2 & 0.8083 & 0.2308 to 2.8313 & 0.7407 & 0.7528 & 0.2207 to 2.5676 & 0.6518 \\
\hline ESR1 & 3.2917 & 1.6312 to 6.6424 & 0.0009 & 3.1300 & 1.6632 to 5.8904 & 0.0004 \\
\hline \multicolumn{7}{|l|}{ Multivariate } \\
\hline Metastasis & 5.2652 & 1.8200 to 15.2323 & 0.0022 & & & \\
\hline ESR1 & 2.5752 & 0.9827 to 6.7484 & 0.0555 & 2.7569 & 1.0204 to 7.4486 & 0.0466 \\
\hline CXCL12 Island 4 & & * & & 7.1355 & 1.6480 to 30.8958 & 0.0089 \\
\hline ER $\alpha$ & & * & & 0.3343 & 0.1247 to 0.8963 & 0.0302 \\
\hline Tumour size & & * & & 1.9577 & 0.7137 to 5.3701 & 0.1942 \\
\hline
\end{tabular}

Abbreviations: HR, hazard ration; Cl, confidence interval; SBR, Scarff-Bloom-Richardson classification; ER $\alpha$, estrogen receptor alpha; PR, progesterone receptor; HER2, Human Epidermal growth factor Receptor-type 2. Statistical significance are in bold. * Variables that were not significant at Cox regression analysis.

status, recurrence or histological type. On the other hand, the stage $(p=0.0003)$, tumour size $(p=0.0029)$, histological grade SBR $(p=0.0011)$, lymph node status $(\mathrm{p}=0.0288)$, oestrogen receptor status $(p=0.0054)$, metastasis $(p<0.0001)$ and death $(p=0.0105)$ were significantly associated with ESR1 gene methylation. Statistical analyses demonstrated a correlation between the intensity of ER $\alpha$ IHC staining and the frequency of ESR1 promoter methylation. Nine out of eleven $(82 \%)$ ER $\alpha$-negative cases were hypermethylated. Based on the results from the immunohistochemical analyses, it should be noted that of the samples scored as 0,15 out of $25(60 \%)$ were methylated; of the samples scored as 1,8 of the $22(36 \%)$ were methylated; of the samples scored as 2,5 of the $16(31 \%)$ were methylated; and of the samples scored as 3, none of the six samples were methylated (Figure 5). The number of unmethylated and methylated samples for the scores were submitted to a statistical Fisher's exact test, and statistical significance $(p<0.0001)$ was obtained (Figure 5). This result with ER $\alpha$-negative status could be due to many mechanisms, including epigenetic mechanisms such as DNA methylation silencing.
These results suggest that in breast cancer patients, silencing of the CXCL12 island 4 and ESR1 genes by promoter hypermethylation can be used as a complementary marker for metastasis risk assessment.

\section{Discussion}

Breast cancer development and progression is influenced by intrinsic properties of the tumour cells, as well as macro-environmental factors. Extensive interplay exists between the tumour cells and signalling molecules such as chemokines. Muller et al. [3] showed that cancer metastasis is a non-random process; organ selectivity by the tumour cells is largely determined by factors that are expressed in remote organs that eventually turn into preferred sites of metastases. Many reports have demonstrated that chemokines are essential factors for the invasion and survival of tumours [2]. However, many other factors, such as the microenvironment of the breast cancer cells and genetic and epigenetic alterations, might be involved. Epigenetic events in tumours cells have the ability to modulate gene expression and the role of epigenetic alterations in cancer progression has been the focus of increasing interest in recent years [24]. 

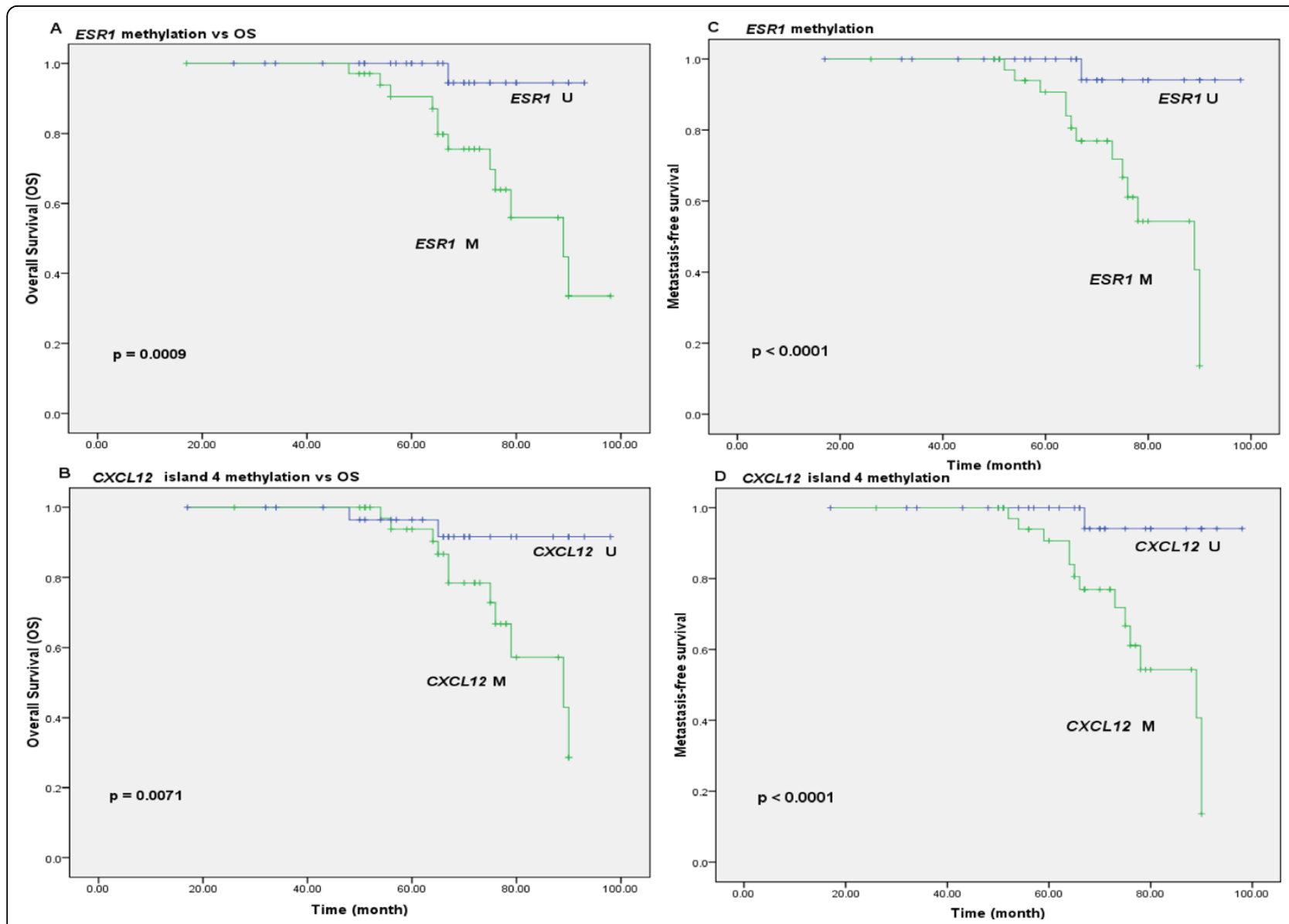

Figure 4 Kaplan-Meier curves for time to breast cancer progression according to CXCL12 methylation status. Kaplan-Meier estimates are shown for overall survival using (A) ESR1 methylation, (B) CXCL12 island 4 methylation, and for metastasis-free survival using (C) ESR1

methylation, (D) CXCL12 island 4 methylation. Symbols on the graph lines represent censored data; $p$ values are given for log rank tests.

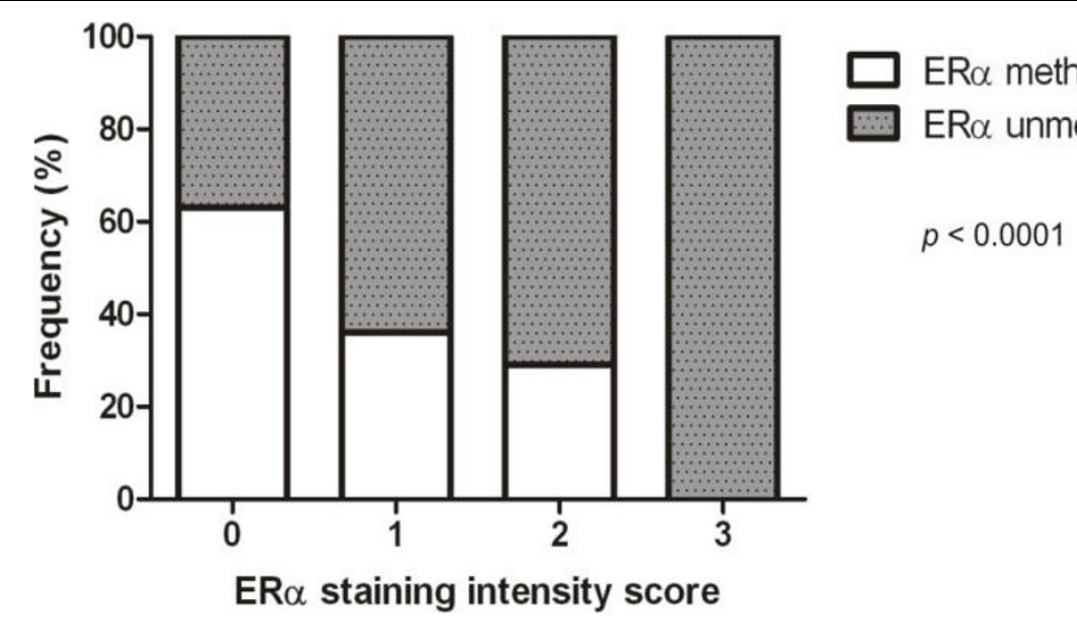

Figure 5 Correlation of ESR1 methylation and protein score staining in the immunohistochemical analysis. The statistical data showed the correlation between intensity of ER $\alpha$ staining by IHC and frequency of ESR1 promoter methylation. The dark bars denote methylated samples and grey bars unmethylated samples. The samples with ER $\alpha$ expression (score 0 to 3, see material and methods) that showed methylation were: scored 0 - 25 with 15 methylated (60\%); score 1 - 22 with 8 methylated (36\%); score 2 - 16 with 5 methylated (31\%), score 3 6 samples without methylation. These results show the percentage of samples that were significant with $p<0.0001$. 
In this study, we assessed the epigenetic regulation of the CXCL12 and ESR1genes in breast cancer samples from Brazilian women. The regulation of CXCL12 expression by promoter hypermethylation is common in colon carcinoma [7] and breast cancer, suggesting that tumour cells that silence CXCL12 are at a selective advantage for metastasis [6,27]. In another recent study, positive correlations between CXCL12 hypermethylation and $E R \alpha$-negative status were reported [27]. One of our objectives was to verify in our samples the methylation findings obtained in other female populations. We evaluated two CpG islands of the CXCL12 gene. The first (island 2) was hypermethylated in ten of 69 (14.5\%) tumour samples. This region had already been analysed by another group that found DNA methylation in five of 15 (33.3\%) American breast cancer samples [6]. In another study [25] with patient samples from a Chinese population, it was verified that 33 of 63 (52.4\%) tumour samples were hypermethylated in the same region. These different results might be due to population or environmental differences. The results for island 2 (Table 1a) showed that no statistical significance was identified for any of the variables. We still do not know if different populations might possess promoter regions that are variable due to SNPs or other mechanisms that can switch genes off.

We have also analysed the CXCL12 5' upstream transcription region in more detail and found a second CpG island we refer to here as island 4 , which is near a DNA consensus site for transcriptional activation. Island 4 is located 565 bps from the region studied by Garcia-Moruja et al. [22], and we speculate that this region is important for transcriptional regulation. However, Antequera and Bird [28] argue that the importance of $\mathrm{CpG}$ islands situated near the TSS is not always obvious, and that new transcripts beginning in $\mathrm{CpG}$ islands distant from the main promoter have been found. Island 4 is located 19 bps away from a 5 " oestrogen responsive element (ERE) binding site. No data exist to prove that these ERE consensus sequences could be functional. However, Lin et al. [29] demonstrated discernable differences between functional and non-functional ERE sites (1234 sites were found) and the CXCL12 gene was one of the oestrogen-responsive genes identified in microarray experiments. Other studies have demonstrated that CXCL12 might be a target for oestrogen receptor binding $[14,30]$. We have concluded that the ERE proximal to island 4 could be involved in the transcriptional regulation of CXCL12. This interaction was modelled by Hall and Korack [14], who suggested that oestrogen activates CXCL12 expression. In this model, CXCL12 binds to the cell surface receptor, CXCR4, in a potentially autocrine and/or paracrine (MAPK cascade) manner, resulting in the activation of cell proliferation.
The MSP results for island 4 (Table $1 \mathrm{~b}$ ) showed a statistical correlation with three variables related to metastasis, reinforcing a probable role for island 4 in the metastatic process. From these variables, we highlight the correlation of island 4 hypermethylation with ESR1 silencing (Table 1c). In order to study this probable correlation, Kaplan-Meier and Cox analyses were performed. These analyses confirm that the silencing of both CXCL12 island 4 and ESR1 genes by DNA hypermethylation and probably the absence of ER $\alpha$, are prognostic factors for metastasis-free survival (Table 3).

The results showed that ESR1 promoter methylation occurred at a higher frequency in samples with methylated CXCL12 island 4 than in samples with methylated island 2 (Figure $3 \mathrm{~B}$ ). In addition, previous studies $[9,10,20,31]$ reported that the ESR1 gene possesses a hypermethylated promoter region. This might explain the correlation found in this study between the hypermethylation of CXCL12 island 4, but not island 2, and the oestrogen receptor negativity. We speculate that these effects are caused by the proximity of the CpG island to an ERE. Curradi et al. [32] observed that the presence of about eight methylated dinucleotides could inhibit transcription because approximately $700 \mathrm{bps}$ of distance is required for chromatin modifications. Therefore, it is possible that the methylation of island 4 could attenuate or even inactivate ERE binding activity.

On the other hand, several studies have also shown the inverse correlation. The absence of ER $\alpha$ could inactivate target genes that possess an ERE site. It is known that $60 \%$ of primary breast tumours are ER $\alpha$-positive, and two-thirds of the advanced tumours do not respond to therapy with anti-estrogens such as tamoxifen $\left(\right.$ Novaldex $\left.^{\odot}\right)$. However, more than a third of patients do not express ER $\alpha$ at the time of diagnosis, and a fraction of tumours that are positive at the time of diagnosis often lose ER $\alpha$ expression [9]. Breast tumour cells in which ER $\alpha$ is absent cannot be regulated by oestrogen, and endocrine therapy is not an option, resulting in a poorer prognosis. Lapidus et al. [33] showed for the first time that ESR1 is inactivated by CpG island DNA methylation in cell lines and primary breast tumours. The same group [31] also used MSP to show that breast cancers expressing ER $\alpha$ had an unmethylated promoter region. Mirza et al. [10] and Zhao et al. [11] detected $66 \%$ and $60 \%$ ESR1 hypermethylation in Indian and Chinese populations, respectively. Thus, the hypermethylation of ER $\alpha$ is commonly seen in several populations and seems to be relevant to hormonal treatment response. According to this, Leu et al. [34] proposed a model suggesting that the progesterone receptor gene $(P G R)$ or another hypothetical target containing an ERE consensus site inside the promoter region becomes hypermethylated and silenced by repressor proteins 
when ER $\alpha$ is not expressed. In other words, ESR1 inactivation and the consequent lack of ER $\alpha$ cause all target genes to become susceptible to epigenetic silencing. Apparently, ESR1 gene silencing by promoter hypermethylation and the consequent absence or decrease of ER $\alpha$ expression are able to lead to CXCL12 gene silencing by hypermethylation.

Consequently, the absence of CXCL12 signals the cells to form metastasis in tumours with a high tumour grade with negative ER $\alpha$ status, increasing the probability of patient death. We do not yet know if island 4 hypermethylation could be involved in the chromatin alterations associated with the blockage of ER $\alpha$ binding, or if the absence of ER $\alpha$ due to epigenetic silencing can contribute to the hypermethylation of CXCL12.

The results presented here show that epigenetic alterations might play an important role in the downregulation of CXCL12 mRNA in breast cancers in Brazilian women. Our results, together with recent findings, emphasise the importance of the CXCL12/CXCR4 signalling axis in the organ-specific patterns of metastasis. Epigenetic events could regulate other genes involved in the development of breast cancer and could also be used to predict a better prognosis. The results presented here could also be interpreted as a cause of the eventual resistance seen in response to endocrine therapy.

\section{Conclusions}

Our results have shown, for the first time, a correlation between hypermethylation of CXCL12 island 4 and ESR1 in patients with histologically advanced cancer, the presence of metastases and death. This correlation could be an important factor in prognosis, cancer prevention and treatment of these patients.

Additional file 1: Overall (OS) and metastasis-free survival (MFS) probabilities calculated by Kaplan-Meier estimates ( $p$ value for log rank test). Kaplan-Meier results for samples.

Click here for file

[http://www.biomedcentral.com/content/supplementary/1471-2407-1023-S1.DOC]

\section{Acknowledgements}

We thank Roseli Prado, Valter Baura and Julieta Pie for technical assistance. Thanks also to Dr. Rubens Silveira de Lima for providing patient material and clinicopathological data. This work was supported by the Brazilian Research Council (CNPq) and CAPES. FFC is supported by the Maeve McNicholas Memorial Foundation.

\footnotetext{
Author details

'Department of Basic Pathology, Federal University of Parana, Curitiba, Brazil. ${ }^{2}$ Laboratory of Molecular Biology and Genomics, Ludwig Institute for Cancer Research, SP, Brazil. ${ }^{3}$ Department of Genetics, Federal University of Parana, Curitiba, Brazil. ${ }^{4}$ Department of Biochemistry and Molecular Biology, Federal University of Parana, Curitiba, Brazil. ${ }^{5}$ Cancer Biology and Epigenomics Program, Children's Memorial Research Center and Northwestern University's Feinberg School of Medicine, Chicago, USA.
}

\section{Authors' contributions}

EASR, carried out the experimental data acquisition, performed data analyses and interpretation and drafted the manuscript. AAC critically revised the manuscript. RS was an undergraduated student and helped with sequencing data collection. KB was the biostatistician in the study. EMSFR and IJC provided patient material and clinicopathological data and critically revised the manuscript. FOP critically revised the manuscript and gave equipment support. EMS critically revised the manuscript and suggested experiments. FFC helped in the experimental design and critically revised the manuscript. GK designed and coordinated the study, supplied administrative support and critically revised the manuscript. All authors read and approved the final manuscript.

\section{Competing interests}

The authors declare that they have no competing interests.

Received: 8 July 2009

Accepted: 28 January 2010 Published: 28 January 2010

References

1. Ben-Baruch A: The multifaceted roles of chemokines in malignancy. Cancer Metastasis Rev 2006, 25(3):357-371.

2. Balkwill F: Cancer and the chemokine network. Nat Rev Cancer 2004, 4(7):540-550.

3. Muller A, Homey B, Soto H, Ge N, Catron D, Buchanan ME, McClanahan T, Murphy E, Yuan W, Wagner SN, et al: Involvement of chemokine receptors in breast cancer metastasis. Nature 2001, 410(6824):50-56.

4. Bird A: DNA methylation patterns and epigenetic memory. Genes Dev 2002, 16(1):6-21

5. Seniski GG, Camargo AA, lerardi DF, Ramos EA, Grochoski M, Ribeiro ES, Cavalli IJ, Pedrosa FO, de Souza EM, Zanata SM, et al: ADAM33 gene silencing by promoter hypermethylation as a molecular marker in breast invasive lobular carcinoma. BMC Cancer 2009, 9:80.

6. Wendt MK, Cooper AN, Dwinell MB: Epigenetic silencing of CXCL12 increases the metastatic potential of mammary carcinoma cells. Oncogene 2007, 27(10):1461-1471.

7. Wendt MK, Johanesen PA, Kang-Decker N, Binion DG, Shah V, Dwinell MB: Silencing of epithelial CXCL12 expression by DNA hypermethylation promotes colonic carcinoma metastasis. Oncogene 2006, 25(36):4986-4997.

8. Giacinti L, Claudio PP, Lopez M, Giordano A: Epigenetic information and estrogen receptor alpha expression in breast cancer. Oncologist 2006, 11(1):1-8.

9. Yang X, Phillips DL, Ferguson AT, Nelson WG, Herman JG, Davidson NE: Synergistic activation of functional estrogen receptor (ER)-alpha by DNA methyltransferase and histone deacetylase inhibition in human ERalpha-negative breast cancer cells. Cancer Res 2001, 61(19):7025-7029.

10. Mirza S, Sharma G, Prasad CP, Parshad R, Srivastava A, Gupta SD, Ralhan R: Promoter hypermethylation of TMS1, BRCA1, ERalpha and PRB in serum and tumor DNA of invasive ductal breast carcinoma patients. Life Sci 2007, 81(4):280-287.

11. Zhao L, Wang L, Jin F, Ma W, Ren J, Wen X, He M, Sun M, Tang H, Wei M: Silencing of estrogen receptor alpha (ERalpha) gene by promoter hypermethylation is a frequent event in Chinese women with sporadic breast cancer. Breast Cancer Res Treat 2008.

12. Stamps AC, Davies SC, Burman J, O'Hare MJ: Analysis of proviral integration in human mammary epithelial cell lines immortalized by retroviral infection with a temperature-sensitive SV40 T-antigen construct. Int J Cancer 1994, 57(6):865-874.

13. Harris RA, Eichholtz TJ, Hiles ID, Page MJ, O'Hare MJ: New model of ErbB-2 over-expression in human mammary luminal epithelial cells. Int $\mathrm{J}$ Cancer 1999, 80(3):477-484.

14. Hall JM, Korach KS: Stromal cell-derived factor 1, a novel target of estrogen receptor action, mediates the mitogenic effects of estradiol in ovarian and breast cancer cells. Mol Endocrinol 2003, 17(5):792-803.

15. Veronesi U, Viale G, Rotmensz N, Goldhirsch A: Rethinking TNM: breast cancer TNM classification for treatment decision-making and research. Breast 2006, 15(1):3-8.

16. Sambrook J, Russel DW: Molecular cloning: A laboratory manual. New York: Cold Spring Harbor Laboratory 2001 
17. Shirozu M, Nakano T, Inazawa J, Tashiro K, Tada H, Shinohara T, Honjo T: Structure and chromosomal localization of the human stromal cellderived factor 1 (SDF1) gene. Genomics 1995, 28(3):495-500.

18. Cartharius K, Frech $K$, Grote K, Klocke B, Haltmeier M, Klingenhoff A, Frisch M, Bayerlein M, Werner T: MatInspector and beyond: promoter analysis based on transcription factor binding sites. Bioinformatics 2005, 21(13):2933-2942.

19. Herman JG, Graff JR, Myohanen S, Nelkin BD, Baylin SB: Methylationspecific PCR: a novel PCR assay for methylation status of CpG islands. Proc Natl Acad Sci USA 1996, 93(18):9821-9826.

20. Li S, Rong M, lacopetta B: DNA hypermethylation in breast cancer and its association with clinicopathological features. Cancer Lett 2006, 237(2):272-280.

21. Costa FF, Paixao VA, Cavalher FP, Ribeiro KB, Cunha IW, Rinck JA Jr, O'Hare M, Mackay A, Soares FA, Brentani RR, et al: SATR-1 hypomethylation is a common and early event in breast cancer. Cancer Genet Cytogenet 2006, 165(2):135-143.

22. Garcia-Moruja C, Alonso-Lobo JM, Rueda P, Torres C, Gonzalez N, Bermejo M, Luque F, Arenzana-Seisdedos F, Alcami J, Caruz A: Functional characterization of SDF-1 proximal promoter. J Mol Biol 2005, 348(1):43-62.

23. Gruber CJ, Gruber DM, Gruber IM, Wieser F, Huber JC: Anatomy of the estrogen response element. Trends Endocrinol Metab 2004, 15(2):73-78.

24. Jones PA, Baylin SB: The fundamental role of epigenetic events in cancer. Nat Rev Genet 2002, 3(6):415-428.

25. Jenuwein $\mathrm{T}$ : The epigenetic magic of histone lysine methylation. FEBS $J$ 2006, 273(14):3121-3135.

26. Yang $X$, Yan $L$, Davidson NE: DNA methylation in breast cancer. Endocr Relat Cancer 2001, 8(2):115-127.

27. Zhou W, Jiang Z, Liu N, Xu F, Wen P, Liu Y, Zhong W, Song X, Chang X, Zhang $X$, et al: Down-regulation of CXCL12 mRNA expression by promoter hypermethylation and its association with metastatic progression in human breast carcinomas. J Cancer Res Clin Oncol 2008 135(1):91-102.

28. Antequera F, Bird A: CpG islands as genomic footprints of promoters that are associated with replication origins. Curr Biol 1999, 9(17):R661-667.

29. Lin CY, Vega VB, Thomsen JS, Zhang T, Kong SL, Xie M, Chiu KP, Lipovich L, Barnett DH, Stossi F, et al: Whole-genome cartography of estrogen receptor alpha binding sites. PLOS Genet 2007, 3(6):e87.

30. Kishimoto $H$, Wang Z, Bhat-Nakshatri P, Chang D, Clarke R, Nakshatri $H$ : The p160 family coactivators regulate breast cancer cell proliferation and invasion through autocrine/paracrine activity of SDF-1alpha/CXCL12. Carcinogenesis 2005, 26(10):1706-1715.

31. Lapidus RG, Nass SJ, Butash KA, Parl FF, Weitzman SA, Graff JG, Herman JG, Davidson NE: Mapping of ER gene CpG island methylation-specific polymerase chain reaction. Cancer Res 1998, 58(12):2515-2519.

32. Curradi M, Izzo A, Badaracco G, Landsberger N: Molecular mechanisms of gene silencing mediated by DNA methylation. Mol Cell Biol 2002, 22(9):3157-3173.

33. Lapidus RG, Ferguson AT, Ottaviano YL, Parl FF, Smith HS, Weitzman SA, Baylin SB, Issa JP, Davidson NE: Methylation of estrogen and progesterone receptor gene 5' $\mathrm{CpG}$ islands correlates with lack of estrogen and progesterone receptor gene expression in breast tumors. Clin Cancer Res 1996, 2(5):805-810

34. Leu YW, Yan PS, Fan M, Jin VX, Liu JC, Curran EM, Welshons WV, Wei SH, Davuluri RV, Plass $C$, et al: Loss of estrogen receptor signaling triggers epigenetic silencing of downstream targets in breast cancer. Cancer Res 2004, 64(22):8184-8192.

\section{Pre-publication history}

The pre-publication history for this paper can be accessed here:http://www. biomedcentral.com/1471-2407/10/23/prepub

\section{doi:10.1186/1471-2407-10-23}

Cite this article as: Ramos et al:: Simultaneous CXCL12 and ESR1 CpG island hypermethylation correlates with poor prognosis in sporadic breast cancer. BMC Cancer 2010 10:23.

\section{Submit your next manuscript to BioMed Central and take full advantage of:}

- Convenient online submission

- Thorough peer review

- No space constraints or color figure charges

- Immediate publication on acceptance

- Inclusion in PubMed, CAS, Scopus and Google Scholar

- Research which is freely available for redistribution

Submit your manuscript at www.biomedcentral.com/submit
Biomed Central 